\title{
EXPERIENCE OF PULHEEMS IN THE 1952 ARMY INTAKE
}

\author{
BY \\ S. ROSENBAUM \\ From the War Office (A.M.D. Stats.), Stanmore, Middlesex
}

(RECEIVED FOR PUBLICATION MAY 10, 1957)

It has long been the custom for the armed Services to grade recruits medically before accepting them for training. Since the war of 1939/45 an elaborate system of grading known as PULHEEMS has been used, and it is now possible to see what it portrays of the young men who have been joining the Forces.

Entrants to the Services are given three medical examinations within five or six months. First a provisional assessment is made by the Ministry of Labour and National Service; then when they are called up, and subsequently at the end of basic training, the Services themselves carry out further examinations of entrants to ensure their fitness for military duties.

The PULHEEMS system codifies the results of the examination by allotting numbers to each of a few descriptive "qualities" whose initials form the title of the system. The only strictly objective qualities are the central letters, $H$ for hearing and $E E$ for eyes, where the results of standard tests are registered on a well-defined scale. This leaves the tail of the word, $M$ (mental capacity), and $S$ (emotional stability), as it were the capacity for thought and feeling, and the head of the word where $U$ and $L$ stand for upper and lower limbs, and $\boldsymbol{P}$ for physique; the latter is associated to some extent with the other qualities. In all these qualities of the head and tail the assessment is of functional capacity to perform a duty. The duty is not specific, and relates to two requirements, eventual fitness for combat and for service in any climate. Standards are changed where appropriate, as for women, and during service perhaps for officers, but we shall not be concerned with these here.

The present analysis is of the PULHEEMS assessment on call-up of the entire Army intake of 1952 and represents only the fittest $80 \%$ of the young male population called up for National Service in that year. With this limitation it is a complete national coverage and can be used as a standard reference for any special group whose physical qualities are to be assessed.

Discharges from the Army due to re-assessment in the first weeks of training are discussed, and include an important group of men who deteriorated in condition since they were first examined. It is shown that the large number of theoretically possible grades reduces to a moderate number in practice, corresponding to recognized defects. The relative importance of these and their likely disposal are examined. Certain associations are shown to exist, as, for example, between hearing and emotional stability.

\section{The Main PULHEEMS Categories}

The numerical scale runs from 1 to 8 , but the full gradation is not used for each quality, neither is there equivalence throughout for a particular number. The simplest is that for acuteness of vision, where the scale corresponds to the divisions of Snellen's test types for each eye separately. Hearing is similarly straightforward, but the gradation is based on a five-point scale, proceeding directly from $1,2,3$ to 7,8 .

For the rest, the PLUMS qualities, we may dismiss 8 as recording unfitness for service in any form, and note that 1 represents an above-average prognostication for the time when a man is fully trained (it is never used for $M$ or $S$ ).

We are left then with 2 , which is the average man (in the colloquial sense) fully suitable as a combatant, and the restricted grades of 3, below average, and 7 , with markedly diminished functional capacity. The numbers 4,5 , and 6 are used only for $P$, and $S$ (6 only), and denote a climatic restriction, so that 4 and 5 imply service in a temperate climate (but fully combatant, corresponding to 1 and 2), while 6 similarly confines the already restricted 3 also to a temperate climate. The number 7 in $P, M$, or $S$ automatically implies service in the United Kingdom 
only, because of a need for treatment or potentiality for breakdown.

The Ministry of Labour and National Service uses the categories Grades I-IV to advise the individual of his state of fitness at the first examination. These correspond to the PLUMS qualities as follows: any 8 implies a Grade IV, as does an $M 7$ or an $S 6$ or 7 . Other $7 \mathrm{~s}$ are Grade III, as are $M 3$ and $P 4,5$, and 6 . Then any other 3 but $M 3$ is Grade II, and any Pulheems " profile" without a 3 or worse is Grade I. The Grade II ( $a$ ) (feet) is used when the only 3 recorded is under $L$.

There is no complication about $H$, which follows the same categories as $U$ and $L$, but the eyes have a special notation which will be described more fully later on. There is no Grade III for eyes, although there is a Grade IV.

Table 1 , recording the results of examinations carried out on call-up, shows the numbers analysed according to the Ministry of Labour and National Service grades, ignoring $E E$, that is to say, certain of those in Grade I may in reality be of a lower grade when vision is taken into account, and so on.

TABLE 1

MINISTRY OF LABOUR CATEGORIES OF ARMY INTAKE FOR 1952

\begin{tabular}{|c|c|c|c|}
\hline 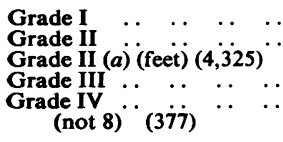 & 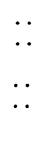 & $\begin{array}{l}\cdots \\
\cdots \\
\cdots\end{array}$ & $\begin{array}{r}136,397 \\
20,028 \\
8,805 \\
892\end{array}$ \\
\hline Total & .. & .. & 166,122 \\
\hline
\end{tabular}

It is known that about one in six men in 1952 were rejected at the original examination by the Ministry of Labour and National Service, and Table 1 therefore represents only the fitter men who had already passed this test. Those in Grade IV in Table 1 may represent a disagreement with the earlier assessment, or a genuine deterioration in condition; in the latter case, the grading on call-up may in fact be higher than that shown in Table 1, where the results of medical boards during the first weeks of service have been incorporated. It will be seen that Grade I men formed $82 \%$ of the intake, and Grade II men $12 \%$, about one-fifth of them on the ground of foot conditions only.

In reflecting upon the physical condition of young men in the country as a whole, taking into account those rejected by the Ministry of Labour and National Service, the picture is roughly as follows:

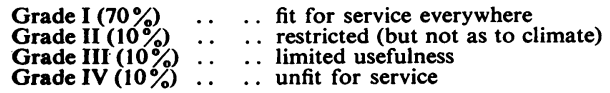

About half of those in Grade III were called up in 1952. (Recruitment of M3 ceased in 1954, and of all Grade III in 1956.)

About $1 \%$ of recruits were discharged from the Army on being re-assessed in their first weeks of training. The rates (per 1,000 intake in 1952) are given in Table 2.

TABLE 2 DISCHARGES FROM ARMY DURING FIRST WEEKS OF

\begin{tabular}{|c|c|c|c|c|}
\hline $\begin{array}{lc}\text { Grade I } & \ldots \\
\text { Grade II } & \therefore \\
\text { Grade II }(a) & (\text { feet }) \\
\text { Grade III } & \ldots \\
\text { Grade IV } & \ldots\end{array}$ & $\begin{array}{l}\cdots \\
\cdots \\
\cdots \\
\cdots\end{array}$ & $\begin{array}{l}\cdots \\
\cdots \\
\cdots \\
\cdots\end{array}$ & 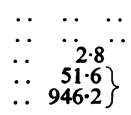 & $\begin{array}{r}1 \cdot 3 \\
21 \cdot 5 \\
133 \cdot 9\end{array}$ \\
\hline Total & .. & . & $\ldots$ & $11 \cdot 5$ \\
\hline
\end{tabular}

In describing the medical categories not by this simple four-grade system but under the PULHEEMS qualities, the number of possible combinations becomes quite large, although many of them do not occur in practice. One simplification is achieved later by analysing $E E$ separately, and another by amalgamating degrees 1 and 2 and also 4 and 5 . When this was undertaken, the great majority of the intake fell into groups as follows in Table 3.

TABLE 3

MAIN PULHEEMS CATEGORIES OF ARMY INTAKE FOR 1952

\begin{tabular}{|c|c|c|c|}
\hline & & Total in Grades & Total Intake \\
\hline Grade I (all 2s) & & 136,397 & 136,397 \\
\hline $\begin{array}{l}\text { Grade II } \\
L 3 \\
P 3 \\
P 3 L 3 \\
U 3 \text { or } P 3 U 3 \\
H 3 \text { or } P 3 H 3 \\
S 3 \text { or } P 3 S 3\end{array}$ & $\begin{array}{r}4,325 \\
9,843 \\
1,939 \\
688 \\
902 \\
1,955\end{array}$ & 19,652 & 20,028 \\
\hline $\begin{array}{c}\text { Grade III } \\
M 3 \\
P 5 \\
P 6 \\
P 3 L 7\end{array}$ & $\begin{array}{r}2,607 \\
2,484 \\
1,012 \\
857 \\
\end{array}$ & 6,960 & 8,805 \\
\hline $\begin{array}{l}\text { Grade IV } \\
P 8 \\
M 7 \\
S 6.7 \text { or } 8\end{array}$ & $\begin{array}{l}187 \\
103 \\
263\end{array}$ & $\frac{553}{163,562}$ & $\frac{892}{166,122}$ \\
\hline
\end{tabular}

It is surprising that over $98 \%$ of the intake should fall into these 14 simple categories when there are many thousands of possible combinations of categories.

Defects of locomotion restricted the capacity to serve of a large number, about a third of those in Grade II. The borderline group in Grade III, men who are with difficulty found jobs, are mainly below average mentally $(M 3)$, or suffer from some disease which makes a tropical climate inadvisable ( $P 5$ and 6). 
Pulheems Qualities Considered Singly

There is much to be learned from a straightforward summary in which each quality is allotted a category irrespective of its cross-associations. In category 1 the numbers were as follows:

$$
\begin{array}{llllr}
P & . . & . . & . . & 873 \\
U & . . & . . & . . & 1,650 \\
L & . . & . . & . . & 1,461 \\
H & . . & . . & . . & 9,683
\end{array}
$$

It is clear that this category is most useful for the quality $H$, where it describes the greatest acuteness of hearing, whereas under $P$, with the recruit's training yet to come, few examining doctors state that they expect him to attain category 1 .

The discharges during selection procedure are related to the intake as denominator, and expressed as rates per thousand in Table 4 . Category 8 is excluded.

\begin{tabular}{|c|c|c|c|c|c|c|}
\hline Degree & $P$ & $U$ & $L$ & $\boldsymbol{H}$ & $M$ & $S$ \\
\hline 1 & $4 \cdot 6$ & 4.8 & 5.5 & $15 \cdot 1$ & & \\
\hline \multirow{2}{*}{$\begin{array}{l}1,2 \\
3 \\
4,5 \\
6 \\
7\end{array}$} & \multirow{2}{*}{$\begin{array}{r}6.7 \\
21.4 \\
23.8 \\
36.3 \\
604.2\end{array}$} & \multirow[t]{2}{*}{$\begin{array}{r}11.0 \\
31.6\end{array}$} & \multirow{2}{*}{$\begin{array}{r}10.1 \\
18.6 \\
100.5\end{array}$} & \multirow{2}{*}{$\begin{array}{l}11 \cdot 1 \\
44.6 \\
76.5\end{array}$} & $\begin{array}{r}9.6 \\
59.9\end{array}$ & $\begin{array}{r}7.4 \\
138.9\end{array}$ \\
\hline & & & & & 993.5 & $\begin{array}{l}111.1 \\
844.0\end{array}$ \\
\hline
\end{tabular}

TABLE 4

DISCHARGES FROM ARMY DURING FIRST WEEKS OF SERVICE OF INTAKE FOR 1952

Those described by $M 7$ are all Grade IV, of course, but so also are those by $S 6$ and $S 7$, and the fact that not all of these were automatically discharged is presumably due to the retention standard being lower than the entry standard in certain corps. There may have been a desire to find a billet for some difficult cases.

When a comparison is made with the discharge rates under Grades I and IV (Table 2) it is seen that Grade I has the low rate of 1.3 per 1,000 . This apparent discrepancy arises because Table 4 includes discharges under qualities other than those indicated in the column headings.

It is interesting to note that two-thirds of all those in $U 7$ were discharged, and this was not through association with a degree 8 in any other quality. $P$ is highly associated with other qualities, but not with other $8 \mathrm{~s}$ in the case of $P 7$, and in fact there is approximately the same high rate for $P 7$ on its own, i.e., combined with degree 2 in the other qualities.

An unusual feature appears in the quality $H$. With the other qualities the discharges are lowest for degree 1, but in the case of $H$ this is not so; the keenest hearers have more discharges per 1,000 than the second category, which comprises the majority of the intake.
EE : Eyes

The eight degrees of this quality correspond as follows to the Snellen visual standards, the right eye being given first.

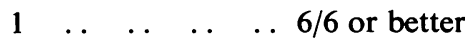

$$
\begin{aligned}
& \begin{array}{llllll}
2 & \ldots & \ldots & . & . . & 6 / 9
\end{array} \\
& \begin{array}{llllll}
3 & \ldots & \ldots & \ldots & . . & 6 / 12
\end{array} \\
& \begin{array}{llllll}
4 & \ldots & \ldots & . . & . . & 6 / 18
\end{array} \\
& \begin{array}{llllll}
5 & \ldots & \ldots & . . & . . & 6 / 24
\end{array} \\
& \begin{array}{llllll}
6 & \ldots & . & . & . & 6 / 36
\end{array} \\
& \begin{array}{llllll}
7 & \ldots & \ldots & . & . . & 6 / 60
\end{array} \\
& 8 \quad \ldots \quad \text {. . less than } 6 / 60
\end{aligned}
$$

For each eye the uncorrected and corrected vision are shown separately in the Pulheems record. Diseases of the eye are assessed under the $P$ quality; only the effect on vision is recorded in the $E E$ quality.

The number of possible combinations is again very large, and this time there is not the same limitation to only a few in practice. It is impracticable to tabulate visual standards in parallel with the other Pulheems qualities.

Each row of Fig. 1 gives the standards of the right eye, and each column the standards of the left eye. Thus there were 1,155 recruits whose uncorrected vision in the right eye was $2(6 / 9)$, and in the left eye $3(6 / 12)$.

The standard of vision corresponding to Grade I is a minimum of degree 3 in each eye when corrected, and almost $97 \%$ are graded I for vision. The minimum standard for Grade II is degree 5 (corrected) in each eye, or as low as 7 in one eye provided that the other is at least 3. Five thousand one hundred and twelve recruits, or about $3 \%$, were in Grade II for vision, but there is no Grade III for vision, and the remaining few were in Grade IV. Not all of these would be automatically rejected for Army service as there is a special provision for those with monocular

\begin{tabular}{|c|c|c|c|c|c|c|c|c|}
\hline \multirow{2}{*}{\multicolumn{2}{|c|}{$\left(\begin{array}{ll}2 & 1\end{array}\right)$ vision }} & exceeds & \multirow{2}{*}{\multicolumn{3}{|c|}{$\left(\begin{array}{ll}1 & 2\end{array}\right)$ vision by }} & \multicolumn{3}{|c|}{ four standard errors } \\
\hline & & , & $\left(\begin{array}{ll}4 & 1\end{array}\right)$ & ," & & two & ," & ", \\
\hline$\left(\begin{array}{ll}1 & 6\end{array}\right)$ & , & ," & $\left(\begin{array}{ll}6 & 1\end{array}\right)$ & ," & ," & three & , & ," \\
\hline$(17)$ & ," & ," & $\left(\begin{array}{ll}7 & 1\end{array}\right)$ & ," & ", & three & ," & ," \\
\hline $9^{0}$ & ", & " & $\left(\begin{array}{l}1 \\
(8\end{array}\right)$ & " & $"$ & two & " & $"$ \\
\hline & & & & & " & & " & "' \\
\hline
\end{tabular}
vision.

The most striking feature of Table 5 is the lack of symmetry between right and left vision. If the difference between a symmetrical pair is judged by a standard error obtained from the square root of their sum, the following discrepancies are obtained between numbers of men with right and left vision.

These differences cannot be dismissed as fortuitous.

TABLE 5

LEFT AND RIGHT VISION 
LEFT EYE

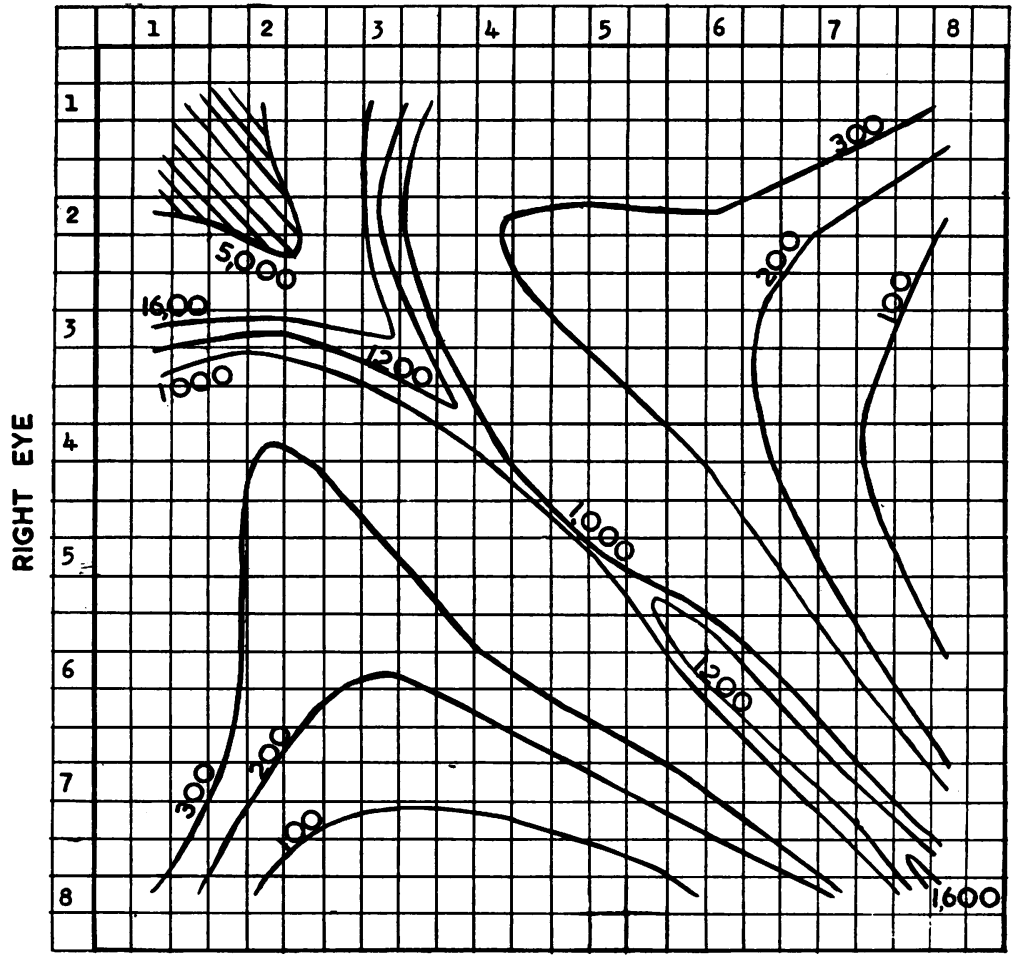

FIg. 1.-Contour diagram illustrating distribution of Army intake for 1952 according to uncorrected vision ( $c f$. Table 5).

Thus we are led either to seek an explanation in the routine of examination or lay claim to a fact.

The apparent excess of people with good eyesight whose right eye is slightly weaker than the left might be the result of the right eye always being examined first, so that Snellen's test types have been partially learnt when the left eye comes to be examined. This, however, does not apply to the remainder, for whom the results were as follows:

(a) Among those whose uncorrected vision in both eyes was very poor, there were rather more whose left eye was the weaker.

(b) Among those with one good eye, whose vision in the other eye was between $6 / 18$ and $6 / 60$, there were more whose left eye was the weaker. The result (b) also holds good for corrected vision.

When discharges are related to intake it is found that the lowest rate $(9 \cdot 5$ per 1,000 as against the average of 11.5 per 1,000 ) is for those whose uncorrected vision is $\left(\begin{array}{ll}1 & 1\end{array}\right)$. In general, the discharge rate increases as the uncorrected vision falls. The same result holds for corrected vision.

\section{H: Hearing}

This quality also records the result of an objective test. The scale is as follows:

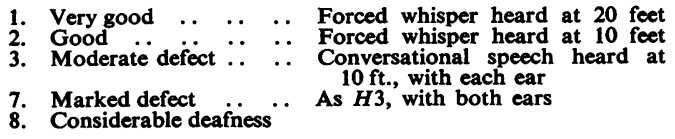

Diseases of the ear are assessed under the quality $P$. Only hearing ability is considered here.

It was observed above (Table 4) that discharges among those with the keenest hearing are greater than among the majority group whose hearing is classed as 2, the other qualities being ignored in the calculation. In order to ascertain whether the same result holds at each level of those qualities, groups were selected whose $U$ and $L$ qualities were 2 , and in which $P$ and $M$ were 2 or 3 , and $S$ was 2,3 , or 7 . The discharge rates per 1,000 intake in these groups were as follows:-

\begin{tabular}{|c|c|c|}
\hline Degree & $H 1$ & $H 2$ \\
\hline $\begin{array}{rll}P & M & S \\
2 & 2 & 2 \\
2 & 2 & 3 \\
2 & 2 & 7 \\
3 & 2 & 2 \\
2 & 3 & 2\end{array}$ & $\begin{array}{r}1.3 \\
275.0 \\
916.7 \\
5.0 \\
145.5\end{array}$ & $\begin{array}{r}1 \cdot 3 \\
159 \cdot 5 \\
820 \cdot 3 \\
7 \cdot 3 \\
31 \cdot 2\end{array}$ \\
\hline
\end{tabular}

Because of the small numbers involved, the only comparisons of significance are for $S 3$ and $M 3$. It is 
concluded that men of very good hearing are more likely to be discharged when there is also an element of below-average stability or dullness. This is not to say that these conditions are necessarily associated in the population at large. Indeed there are fewer in proportion among those designated M3 of those with the acutest hearing.

A systematic study of these associations has been carried out by tabulating the expected numbers for each combination of pairs of qualities and noting the differences from those observed, based on a standard error of the square root of the expected number. This study reveals that poor hearing is associated with stability below the average, while acute hearing is associated with more extreme instability. Poor hearing is also associated with a below-average mentality but acute hearing is notindeed, the contrary is very marked. But, as already noted, there are more discharges in the group that has this combination than among the $H 1 M 2$ group.

The association is marked between poor hearing and a low $P$ assessment, partly because climatic restrictions are made on the $P$ quality and because a defect of hearing due to disease is classified under both qualities.

\section{$M$ and S: Mental Capacity and Emotional Stability}

$M$ is judged on record and on clinical impression, and is an assessment of suitability rather than of intelligence as judged by mental tests. In effect there were only two categories serving, since $M 7$ were all discharged; these were the Grade I, M2, and the Grade III, $M 3$.

$S$ is more complex, since it is sometimes connected with other qualities, and may even be detected only through them. $S 3$ counts as Grade II, but it is not acceptable in regular recruits. $S$ is the only quality other than $P$ that uses degree 6 , but not 5 , since this quality denotes that a recruit is not suited for service in any climate nor is he fitted to be a combatant.

The $M$ and $S$ scales are interdependent to some extent, since the policy is to grade the dullard as $S 8$ if he is unstable as he is of no use for military service; therefore the combination of $M 3$ and $S 3$ is seldom used. The associations with $H$ are referred to in the previous section on hearing.

There is an association of lower grade mentality with lack of dexterity of the upper limbs and another with a restricted physical grading: there is no administrative instruction to account for this. Also an under-representation of $P 5$ and $P 6$ indicates that climatic restrictions are not commonly awarded to the duller men, and seems to suggest that disabilities can be divided into two groups, one of which causes the positive association above, while the other is the reverse and is a group sensitive to tropical climates.

The association of instability with below-average $P$ is strong, since the psychosomatic disorders impinge on both.

\section{P, U, and L: Physique, Upper and Lower Limbs}

The associations of these qualities with hearing, mental capacity, and emotional stability have already been discussed.

$U$ stands for the upper limbs and their operation, which may be governed by a condition affecting $P$ also; similarly with $L$. In the latter case, a defect such as flattened arches will only affect the grading if the function is impaired. There are no negative associations in these categories, and $P$ naturally tends to be affected by $U$ and $L$, as in the practice of awarding $P 8$ with $U 8$ and $L 8$. Associations which involve $P 6$ indicate a restriction to temperate climates, as, for example, in subjects with hyperhidrosis. The qualities $U$ and $L$ do not in themselves register a climatic restriction. Their distribution in the remainder of the scale is dissimilar; in fact a much greater use is made of the lower categories for $L$ than for $U$.

As an illustration of the association between qualities it may be noted that 1,085 recruits out of a total of 166,122 had a markedly diminished locomotor efficiency and were graded $L 7$. But there were no fewer than 916 of these L7s among the 14,377 who were graded $P 3$.

The last of the associations to consider is that between $U$ and $L$. This association is based on the large number of $P 3 \mathrm{~s}$ who are both $U 3$ and $L 3$; this means that $P 3$ is almost invariably awarded when the combination of $U 3$ and $L 3$ occurs, and suggests a common constitutional origin.

The quality $\boldsymbol{P}$ may be considered separately. In Table 6 the term "combined" denotes association with a degree of 3 or lower in another quality.

TABLE 6

NUMBERS IN $P$ CATEGORIES IN ARMY INTAKE FOR 1952

\begin{tabular}{c|r|r}
\hline$P$ Category & Alone & Combined \\
\hline 2 & 136,397 & 10,429 \\
3 & 9,843 & 4,534 \\
5 & 2,484 & 452 \\
6 & 1,012 & 364 \\
7 & 144 & 137 \\
8 & 187 & 139 \\
\hline & 150,067 & 16,055 \\
\hline
\end{tabular}

Among those with a below-average physique, for every combined classification, such as $P 3 L 3$, there are rather more than two where $P$ is low on its own. About a quarter of those are so graded for conditions where a service in a temperate climate is 
recommended, for example, in certain skin diseases and otitis media. Some respiratory diseases also affect grading in this way, when not sufficiently severe to justify a $P 7$ or 8 . Height and weight are judged within wide limits for natural variation. The height and weight of Army recruits, the measurement of which is part of the PULHEEMS examination, have been analysed elsewhere (Rosenbaum, 1954).

\section{Summary}

The initials of the word PULHEEMS stand for the physical and mental qualities which are judged in medical examinations of recruits to the armed Forces. A numerical grading is used for each letter, and this paper analyses the results of examinations of the whole of the 1952 Army intake. Although numerous combinations of grading are possible, the great majority fell into 14 groups. These are not much more complex than the four grades used by the Ministry of Labour and National Service to describe his medical condition to the recruit himself and are far more revealing of causes.

Correlations were found between various qualities: in particular, the quality $P$ was strongly associated with other qualities, sometimes on account of a constitutional ailment that had a local effect. Psychosomatic disorders accounted to some extent for the association of emotional instability with physical defects. Associations were found between - mental capacity and the physical qualities.

There were also associations of hearing with emotional instability and low mentality, both in those of poor hearing and of extremely acute hearing.

\section{REFERENCE}

Rosenbaum, S. (1954). J. Roy Stat Soc., Series A, 117, 331. 